\title{
PRODUCTION OF PROTOTYPE PARTS USING DIRECT METAL LASER SINTERING TECHNOLOGY
}

\author{
Josef Sedlak ${ }^{a, *}$, Vit Sekerka $^{a}$, Martin Slany $^{a}$, Karel Kouril $^{a}$, \\ Oskar ZemCiK ${ }^{a}$, Josef Chladil ${ }^{a}$, Lubos Rozkosny ${ }^{b}$ \\ ${ }^{a}$ Department of Machining Technology, Institute of Manufacturing Technology, Faculty of Mechanical \\ Engineering, Brno University of Technology, Technicka 2896/2, Brno 61669, Czech Republic \\ ${ }^{b}$ Innomia a.s., Husova 114, Jaromer 55101, Czech Republic \\ * corresponding author: sedlak@fme.vutbr.cz
}

\begin{abstract}
Unconventional methods of modern materials preparation include additive technologies which involve the sintering of powders of different chemical composition, granularity, physical, chemical and other utility properties. The technology called Rapid Prototyping, which uses different technological principles of producing components, belongs to this type of material preparation. The Rapid Prototyping technology facilities use photopolymers, thermoplastics, specially treated paper or metal powders. The advantage is the direct production of metal parts from input data and the fact that there is no need for the production of special tools (moulds, press tools, etc.). Unused powder from sintering technologies is re-used for production $98 \%$ of the time, which means that the process is economical, as well as ecological.

The present paper discusses the technology of Direct Metal Laser Sintering (DMLS), which falls into the group of additive technologies of Rapid Prototyping (RP). The major objective is a detailed description of DMLS, pointing out the benefits it offers and its application in practice. The practical part describes the production and provides an economic comparison of several prototype parts that were designed for testing in the automotive industry.
\end{abstract}

KEYWORDS: rapid prototyping; DMLS; prototype; 3D print; laser.

\section{AdDitive TECHNOLOGY OF RAPID PROTOTYPING}

Rapid Prototyping (RP) is a progressive group of methods used to achieve the fastest possible development of models, prototypes and components directly based on 3D data. RP emerged in the 1980s, namely in 1986, when the American company 3D Systems came with stereolithography technology. Since then the development has well advanced and physical models can be made of resin, thermoplastic, wax or metal powder, depending on the type of technology used.

The selection of a suitable RP technology is highly dependent on the desired properties and purpose of the final part, such as product design assessment, inspection of assembly, ergonomics or implementation of functional tests [1, 2].

Currently, the device for RP not only creates models and prototypes, but it is also used in the production of tools, moulds and parts for small series production. It is mainly used in the area of aircraft engineering, aerospace, defence, automotive industry, consumer electronics, toys, medicine and many others. In all areas, shorter development times have been achieved along with a reduction of costs and an improvement of product quality 3 .

\section{DMLS ADDITIVE METHOD}

DMLS is a revolutionary RP additive method based on the principle of gradual melting of ultrafine layers of metal powder using a laser beam. It allows a fast production of fully functional metal parts (see Fig. 1) directly from 3D CAD data. There is therefore no investment in production tools and technologies, which results in considerable savings in terms of cost and mainly time. This method was developed in 1995 by the German company Electro Optical Systems (EOS) in collaboration with Rapid Product Innovations (RPI). In its time it was the first commercial RP method which was able to produce metal parts in a single process. DMLS now allows the simultaneous production of several differently shaped parts and also offers a wide range of properties, from controlled porosity for ventilation or filtration, to fully homogenous structures, which can achieve a greater strength than castings or forgings [4, 5].

\subsection{Principles of the DLMS ADditive METHOD}

Preprocessing. Prior to the production of each respective part, 3D CAD data must be first imported into the EOSTATE Magics process software. After that, a machine operator suggests an optimal production position of the part and selects the appropriate thickness of sintered layers. A correct choice of layer 


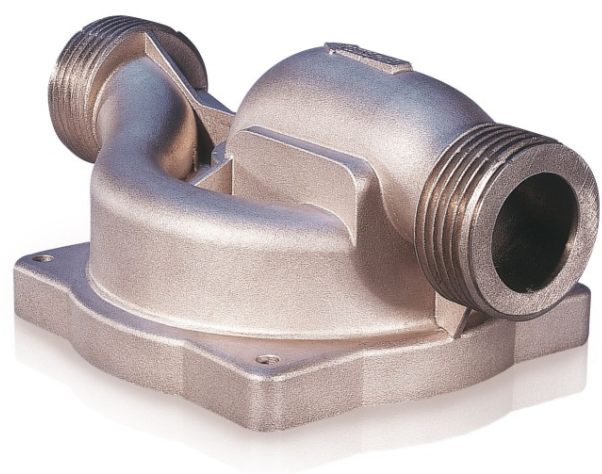

Figure 1. A metal part produced by the DMLS additive method [6].

thickness $(0.020 \mathrm{~mm}$ or $0.040 \mathrm{~mm})$ is especially important with regard to the accuracy and speed of production - a thinner layer means greater accuracy, but it increases the production time. Finally, the software assigns the correct technological parameters of the structure, depending on the type of selected material, and "cuts" 3D data into individual layers 4 .

Processing. The layered $3 \mathrm{D}$ data are sent to the production machine, in whose working chamber a steel platform is clamped, and where manufactured components are constructed (Fig. 2). The manufacturing process itself begins with a dosing device setting the amount of powder for a single layer. An arm with a ceramic blade spreads an even layer of powder, according to the selected thickness, over the surface of a steel platform. A machine controlling software runs the laser beam variable focusing along with its trajectory from the part geometry point of view, i.e., the coordinates $\mathrm{X}$ and $\mathrm{Y}$. The controlling of the $\mathrm{Z}$ axis is using the platform shifting by $20 \mu \mathrm{m}$ with each change of the layer enables a shaped tolerances compliance in the range of $0.1 \mathrm{~mm}$. In the area of laser beam incidence (output from 200 to $400 \mathrm{~W}$ ), metal powder is locally melted, which leads to its "in-melting" to the underlying layer and subsequent solidification to a solid state. During the construction of each part, it is necessary to fix the part in the correct position using a support structure, which is anchored to the base steel platform and is constructed along with the product. The steel platform also dissipates the heat generated during sintering so that the molten metal solidifies very quickly. For most of the materials used, the machine working chamber is filled with nitrogen to protect the manufactured parts from oxidation [4, 5].

Postprocessing. After completing the production process, the platform with products is removed from the workspace and the parts are separated from the platform. Unmelted powder is transferred by suction into the hopper and $98 \%$ of it is re-used for further production. Finishing operations are an essential part of the production process. First, it is necessary to

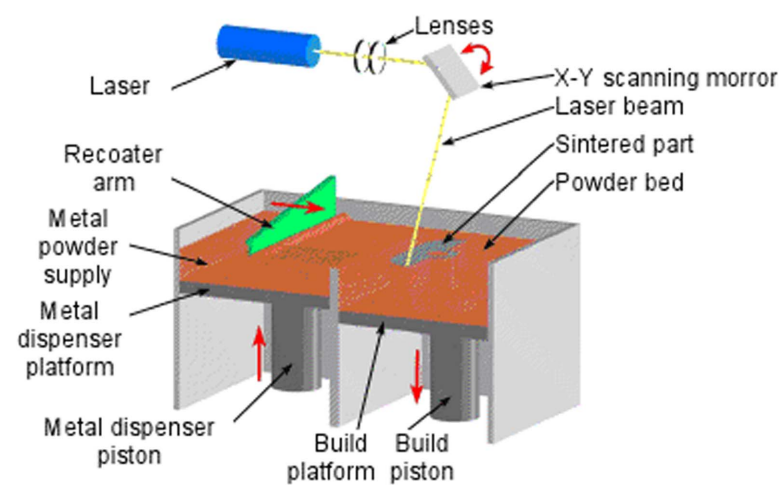

FIGURE 2. Principles of the DMLS additive method [7].

remove the support structures from the product surface, and then the surface can be further blasted, ground, polished or machined in the same way as the traditional metal material [5].

\subsection{USE OF THE DLMS ADDITIVE METHOD IN PRACTICE}

The spectrum of applications of the DMLS additive method is very wide - from prototypes through small series parts to the final, customized products. The advantages of the process are growing together with the complexity of the shape of the parts; the more complex the geometry of the product in terms of shape and frequency of details, the more economically efficient the DMLS additive method is compared to conventional methods. The possibility of direct production of intricate parts, which in classical technologies must be produced from several parts, brings savings in production costs, shortens assembly times and increases reliability. The DMLS process enables us to apply tiny structural variations to each individual component, that is, to manufacture products optimized according to individual customer requirements. Re-use of unmelted powder for further production makes this process not only economical, but also ecological [4, 5].

DMLS is gradually gaining the position of a manufacturing method for both rapid and accurate production of fully functional prototype parts or finished products. The $3 \mathrm{D}$ printing process creates highly durable, yet delicate components that are used in many industries such as aerospace, automotive and electronic industries, medicine, consumer goods and many more. The process offers a wide range of applications, mainly in the area of moulds and tools for the manufacture of plastic or metal products prototype moulds, moulds for small series production, complex-shaped inserts, and cores with cooling channels for faster heat removal. Especially in the plastics industry, a suitable application of the DMLS additive method can shorten the production times of moulds, increase process productivity, and thus also improve the quality of parts [5].

The scope of the DMLS additive method is very broad and constantly growing. This method is rel- 

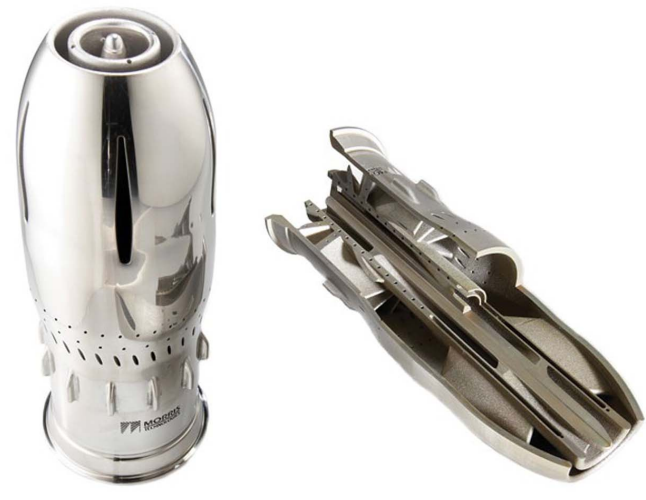

FiguRE 3. Fuel injection nozzle of an aircraft turbine [7.

atively new (about 18 years) and its potential use has not been sufficiently explored. With the everincreasing speed of devices and the ever-expanding number of materials, the range of possible applications also increases [5].

Application in automotive and aerospace industries. The DMLS additive method is only one of the many RP methods. It is used in the aerospace and automotive industries for the development and manufacturing of components. Examples of these components in the aerospace industry include engine parts, turbine blades with a complex internal geometrical structure, as well as various components in the cockpit of aircrafts, or fuel injection nozzles (Fig. 3). The automotive industry also offers opportunities for a very wide use, particularly as part of crash tests, components for functional and assembly verification (hood hinges, lock systems), or high-stress components in racing cars. It can also be found in luxury cars in the form of various design elements of complex shapes. The main reasons for the application of the DMLS additive method in these sectors are speed and economic efficiency, combined with the geometric complexity of the manufactured parts.

Application in medicine. In recent years, the use of the DMLS additive method has been widely traced in medicine, particularly because of patients' customized requirements, which can be satisfied by this method. Currently, metal powder is mainly used for the production of various kinds of implants, dental prostheses, intricate surgical instruments and parts for medical devices. The required 3D data for arrangement of the model and a follow-up print are obtained by computer tomography or by reverse engineering technology [8].

An interesting example could be the knee joint implant which was manufactured by the Innomia PLC Company as part of Josef Sedlak's habilitation thesis. The objective was to verify whether it is possible to

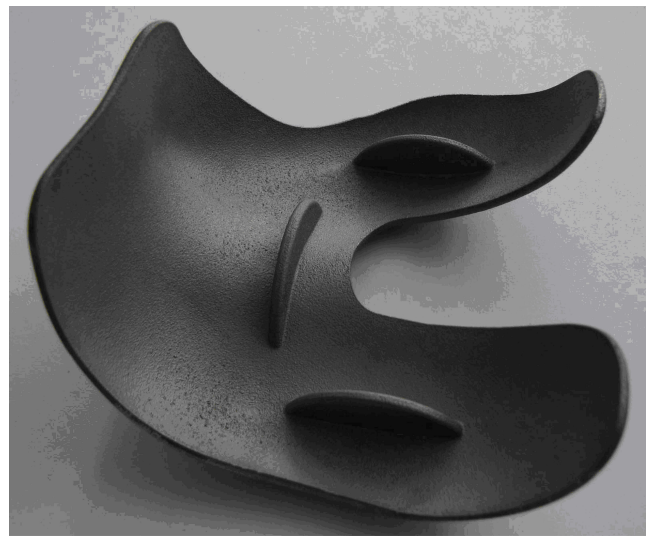

Figure 4. Knee joint implant [8].

produce a knee replacement (see Fig. 4) whose external shape is the same as that of currently applied implants and whose internal shape precisely copies the surface of the knee joint - being therefore the negative of the knee joint surface. Due to the shaping of the inner surfaces of the implant, it is expected to reduce the burden on the patient and to maintain bone mass for a potential revision surgery. The current replacements are a compromise between anatomical and physiological functions and technical capabilities of manufacturers. After many consultations with surgeons and orthopaedic surgeons for instance in St. Anne's Hospital in Brno, a joint replacement has been designed specifically for the individual patient. As a source for creating a 3D model of the patient's knee, the output CT data from computer tomography were used and further modified for the desired prototype implant [8].

\section{Production of PRototype parts}

Prototypes for any application are currently manufactured in a large number of companies, each of which uses a variety of methods - from conventional ones such as machining, welding, casting, or bulk and sheet metal forming, to unconventional methods such as the above-mentioned DMLS additive technology. Nowadays, the correct method choice depends mainly on the shape complexity of the part, on its strength, its application and also on the speed with which the prototype is manufactured. It is the speed of production which represents a large potential of the DMLS method compared with the aforementioned conventional technologies.

The automotive industry is one of the sectors which draw on the advantages of RP and specifically of the DMLS additive method. Therefore, the practical part of this contribution deals with the production and economic comparison of several prototype parts, which have been used, in particular, in motoring. The prototypes that are compared here would normally be produced by moulding, which would involve processes such as pressing, bending, shearing, etc. Special preparations and tools would have to be produced; these 


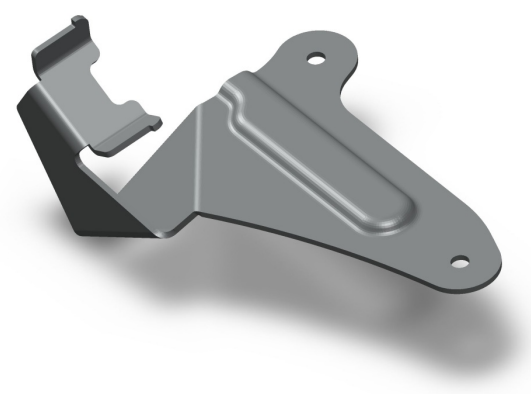

FigURE 5. Prototype 01; dimensions $200 \times 128 \times 2 \mathrm{~mm}$.

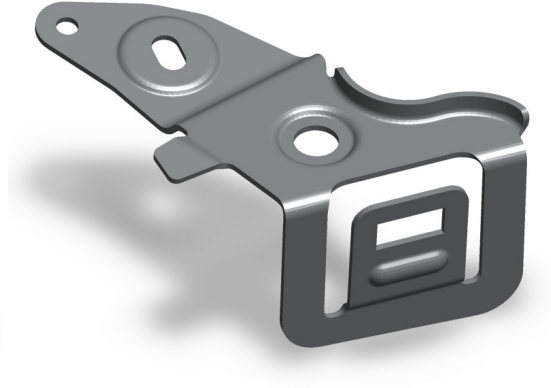

FIGURE 6. Prototype 02; dimensions $140 \times 70 \times 1.5 \mathrm{~mm}$.

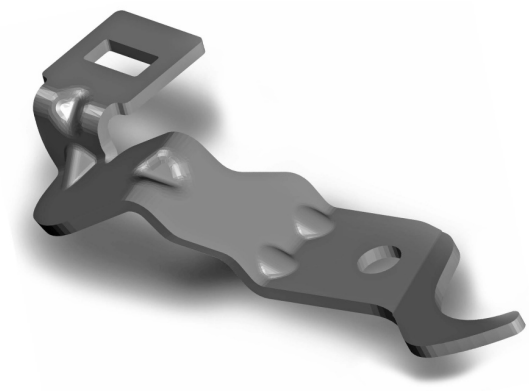

FiguRe 7. Prototype 03; dimensions $110 \times 45 \times 2 \mathrm{~mm}$.

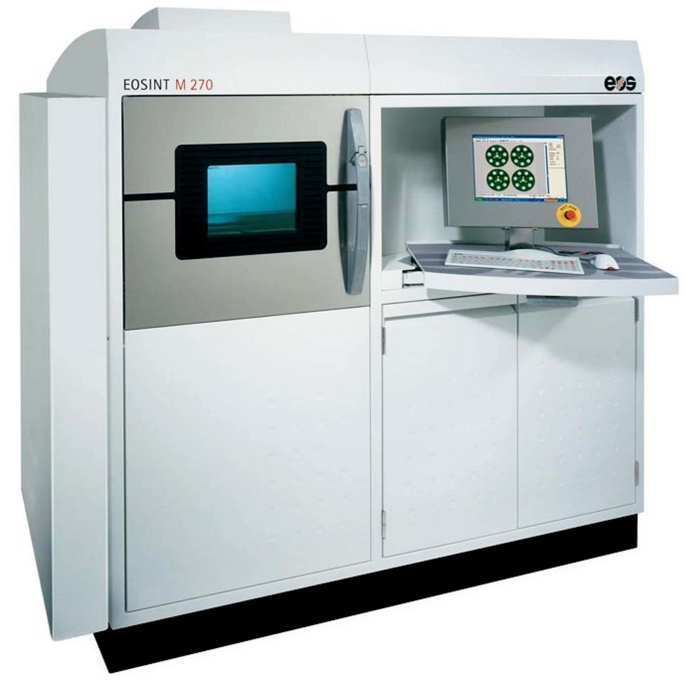

Figure 8. EOSINT M270 [6].

would considerably lengthen the entire production process and make it also more expensive. Their financial and time benefit would only be meaningful for a larger number of pieces, but not for the production of several prototypes for functional or other tests.

\subsection{Manufactured Parts}

The following parts have been produced in certain quantities, and served as functional and test prototypes. The specific purpose and function of these parts cannot be referred to due to confidentiality of development. The parts are of various complex shapes so that the comparison with forming technologies is relevant.

To get an idea of the size of the individual parts, their dimensions are given in an unfolded state (length $\times$ width $\times$ thickness). Giving the exact dimensions would be misleading because of their complexity. 3D models of manufactured prototypes are shown in Fig. 5 . Fig. 6 and Fig. 7

\subsection{Production process using the DLMS METHOD}

The production of the above parts was carried out in Innomia PLC Company, which offers a complete

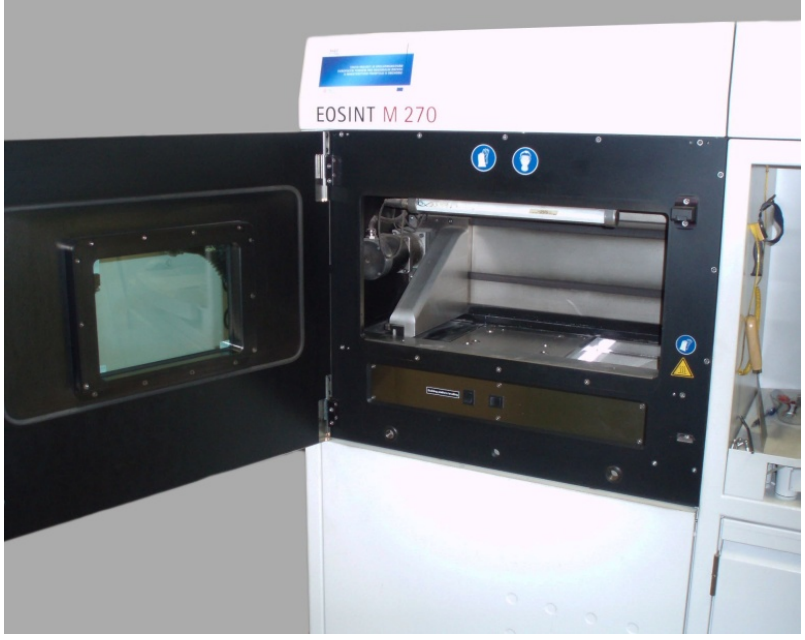

FIgURE 9. View of the production chamber EOSINT M270 6].

service in the development of plastic and metal parts, using RP additive technologies. The input data were supplied by the prototype contract owner only in *.stl format and production documentation was supplied only shortly because it is not necessary for this type of production. The data were checked and possibly adjusted in the RP Magics software so that the polygonal model perfectly closed the volume, and all the cuts generated from it had a closed contour.

EOSINT M270 production device. For the manufacturing of parts the EOSINT M270 device, which is the first device of this kind in the Czech Republic, was used (see Fig. 8). It was introduced to the market in 2004 as a successor to EOSINT M250 and is produced by the German company EOS, which invented the DMLS method. The device allows a rapid production of fully functional prototype parts from 3D data and also offers a wide range of features such as a fully homogeneous structure, which can achieve higher strength than castings and forgings 4 . A view of the EOSINT M270 production chamber is shown in Fig. 9 . 


\begin{tabular}{ccccccccc}
\hline $\mathrm{C}$ & $\mathrm{Si}, \mathrm{Mn}$ & $\mathrm{P}, \mathrm{S}$ & $\mathrm{Cr}, \mathrm{Cu}$ & $\mathrm{Al}$ & $\mathrm{Mo}$ & $\mathrm{Co}$ & $\mathrm{Ni}$ & $\mathrm{Ti}$ \\
\hline $\max .0 .03$ & $\max .0 .10$ & $\max .0 .01$ & $\max .0 .50$ & $0.05-0.15$ & $4.50-5.20$ & $8.50-9.50$ & $17.00-19.00$ & $0.60-0.80$ \\
\hline
\end{tabular}

TABLE 1. Chemical composition of tool steel [wt\%] [9].

\begin{tabular}{lccccccc}
\hline & \multicolumn{3}{c}{ DMLS additive method } & & \multicolumn{3}{c}{ Forming technology } \\
\cline { 2 - 4 } \cline { 7 - 8 } & Pieces & Price & Price $/ \mathrm{pc}$ & & Pieces & Price & Price/pc \\
\hline Price of part & $1 \mathrm{pc}$ & $25680 \mathrm{CZK}$ & $25680 \mathrm{CZK}$ & & $1 \mathrm{pc}$ & $4800 \mathrm{CZK}$ & $83200 \mathrm{CZK}$ \\
& $2 \mathrm{pcs}$ & $34200 \mathrm{CZK}$ & $17100 \mathrm{CZK}$ & & $2 \mathrm{pcs}$ & $6400 \mathrm{CZK}$ & $42400 \mathrm{CZK}$ \\
& $4 \mathrm{pcs}$ & $50800 \mathrm{CZK}$ & $12700 \mathrm{CZK}$ & & $4 \mathrm{pcs}$ & $7200 \mathrm{CZK}$ & $21400 \mathrm{CZK}$ \\
\hline Price of tool & \multicolumn{3}{c}{-} & & $38400 \mathrm{CZK}$ \\
\hline Time of delivery & \multicolumn{3}{c}{$2-3$ days } & & $3-5$ weeks \\
\hline
\end{tabular}

TABLE 2. Economic comparison of Prototype 01 production [10].

\begin{tabular}{lccccccc}
\hline & \multicolumn{3}{c}{ DMLS additive method } & & \multicolumn{3}{c}{ Forming technology } \\
\cline { 2 - 3 } \cline { 6 - 8 } & Pieces & Price & Price/pc & & Pieces & Price & Price/pc \\
\hline Price of part & $1 \mathrm{pc}$ & $13140 \mathrm{CZK}$ & $13140 \mathrm{CZK}$ & & $1 \mathrm{pc}$ & $5880 \mathrm{CZK}$ & $98980 \mathrm{CZK}$ \\
& $2 \mathrm{pcs}$ & $16500 \mathrm{CZK}$ & $8250 \mathrm{CZK}$ & & $2 \mathrm{pcs}$ & $7950 \mathrm{CZK}$ & $50530 \mathrm{CZK}$ \\
& $4 \mathrm{pcs}$ & $24700 \mathrm{CZK}$ & $6180 \mathrm{CZK}$ & & $4 \mathrm{pcs}$ & $9300 \mathrm{CZK}$ & $25600 \mathrm{CZK}$ \\
\hline Price of tool & \multicolumn{3}{c}{-} & & \multicolumn{3}{c}{$93100 \mathrm{CZK}$} \\
Time of delivery & \multicolumn{3}{c}{2 days } & & \multicolumn{3}{c}{$5-7$ weeks } \\
\hline
\end{tabular}

TABle 3. Economic comparison of Prototype 02 production [10].

Used material - tool steel (MS1). The parts were made of tool steel (see Fig. 5, which has excellent mechanical properties. The martensitic steel in the form of fine powder carries the company brand of EOS MS1. The steel composition of German X3NiCoMoTi 18-9-5 corresponds to European Classification 1.2709. A very high strength and surface hardness characterize the MS1. Parts made from this material have a homogeneous structure with a hardness of 36-39 HRC. MS1 is commonly used for the production of moulds, tools and high stress components and prototypes [5, 9]. The chemical composition of the steel is shown in Tab. 1

Properties [9]:

- good machinability and thermal conductivity;

- construction speed of $2-4 \mathrm{~mm}^{3} \mathrm{~s}^{-1}$;

- ultimate tensile strength $\mathrm{Rm}=1100 \mathrm{MPa}$ (up to $1950 \mathrm{MPa}$ after upgrading);

- yield strength $\mathrm{Rp}_{0.2}=1000 \mathrm{MPa}$ (up to $1900 \mathrm{MPa}$ after upgrading);

- recommended minimum layer thickness of $40 \mu \mathrm{m}$;

- maximum working temperature of $400{ }^{\circ} \mathrm{C}$;

- surface hardness of 36-39 HRC (50-54 HRC after upgrading).

\subsection{ECONOMIC COMPARISON OF PRODUCTION}

Here you can find a comparison of the economic demands of manufacturing the parts using the DMLS additive method versus forming technology. The comparison was carried out for the production of 1,2 and 4 pieces. A given component was manufactured in one piece only to test the functionality; other parts in a higher number for various test purposes and deformation tests [10.

Prototype parts were not actually produced by forming technologies; only an economic analysis and pricing of their production was carried out by conventional technologies. The pricing of parts and tools for forming was performed by the PWO UNITOOLS CZ plc company, which deals with prototype and, in particular, mass production of metal stampings and assemblies for the automotive industry on a long term basis. Due to continuous improvement, to its use of new technologies and certifications according to VDA, it reaches the level of world-class suppliers [10].

A financial comparison of each prototype part made using the above-mentioned production methods (forming technology, DMLS additive method) is shown in Tab. 2. Tab. 3and Tab. 4 These tables always list the price of a part for the respective number of pieces, the price of the tools necessary for production by forming and also the approximate time range within which the parts are produced. The price per piece was calculated as a quotient of the total price and the number of pieces. In the case of forming, it is necessary to add the cost of the tool so that the price per piece is relevant and realistic 10 .

Here is an example of the calculation of the price 


\begin{tabular}{lccccccc}
\hline & \multicolumn{3}{c}{ DMLS additive method } & & \multicolumn{3}{c}{ Forming technology } \\
\cline { 2 - 4 } \cline { 7 - 8 } & Pieces & Price & Price $/ \mathrm{pc}$ & & Pieces & Price & Price/pc \\
\hline Price of part & $1 \mathrm{pc}$ & $8080 \mathrm{CZK}$ & $8080 \mathrm{CZK}$ & & $1 \mathrm{pc}$ & $2450 \mathrm{CZK}$ & $58250 \mathrm{CZK}$ \\
& $2 \mathrm{pcs}$ & $9340 \mathrm{CZK}$ & $4670 \mathrm{CZK}$ & & $2 \mathrm{pcs}$ & $3920 \mathrm{CZK}$ & $29860 \mathrm{CZK}$ \\
& $4 \mathrm{pcs}$ & $13950 \mathrm{CZK}$ & $3490 \mathrm{CZK}$ & & $4 \mathrm{pcs}$ & $4900 \mathrm{CZK}$ & $15175 \mathrm{CZK}$ \\
\hline Price of tool & \multicolumn{3}{c}{-} & & $55800 \mathrm{CZK}$ \\
\hline Time of delivery & \multicolumn{3}{c}{2 days } & & \multicolumn{3}{c}{$3-5$ weeks } \\
\hline
\end{tabular}

TABLE 4. Economic comparison of Prototype 03 production [10].

\begin{tabular}{ccccccccc}
\hline $\mathrm{C}$ & $\mathrm{Si}$ & $\mathrm{Mn}$ & $\mathrm{P}$ & $\mathrm{S}$ & $\mathrm{Al}$ & $\mathrm{Nb}$ & $\mathrm{V}$ & $\mathrm{Ti}$ \\
\hline $\max .0 .12$ & $\max .0 .50$ & $\max .1 .50$ & $\max .0 .025$ & $\max .0 .020$ & $\min .0 .015$ & $\max .0 .09$ & $\max .0 .20$ & $\max .0 .15$ \\
\hline
\end{tabular}

TABLE 5. Chemical composition of steel with higher yield stress for cold forming: S355MC [wt\%] [11].

per piece for forming technology considering the total production of four prototype 01 pieces:

$$
\begin{aligned}
& \text { (price of tool }+ \text { price of } 4 \text { pieces of proto- } \\
& \text { types }) / \text { number of pieces }=\text { price per piece, } \\
& (78400 \mathrm{CZK}+7200 \mathrm{CZK}) / 4=21400 \mathrm{CZK} \text {. }
\end{aligned}
$$

\section{Discussion}

Nowadays prototype production is realized with the help of programmable power and hydraulic brakes or with the help of a 3D laser technology that provides a high accuracy, minimal heat deformation and high-speed machining of metal parts. Afterwards it is necessary to produce various clamping or control jigs and tools for plate forming, which is the largest production item. Specific methods of prototype production may differ and always depend on the given part and its use.

The material that was used for the forming technology is a steel with a higher yield stress for cold forming: S355MC. The chemical composition of the steel is given in Tab. 5 .

The production material of the DMLS additive method was the EOS MS1 tool steel (see 3.2.2). One kilogram of tool steel costs approximately $4300 \mathrm{CZK}$. The setting of the price of prototype parts according to data volumes of individual models in STL format is a part of the company know-how. There are also other factors influencing the total price, for instance the parts orientation in the machine printing room, the creation of supporting structures, the fixation of parts and their platform allocation.

The material prices and operating costs of the machine have been included in the economic analysis (see 3.3).

In Fig. 10 there are also visible financial differences in the prototype price per unit in the case of the production of four parts. The prototype price for certain numbers of prototypes, as well as the delivery time have been compared. From this comparison the
DMLS additive method comes out as the best one because it is several times cheaper when it comes to the production of most parts, and the delivery takes a few days as opposed to a few weeks for the forming technology. In its current form, the DMLS additive method offers a lot of advantages. Even though this method was founded 15 years ago, it is still not well-known and its indisputable advantages are often neglected.

As is clearly visible from the price comparison, the DMLS additive method is significantly cheaper especially when the production of one prototype only is needed. However, also in cases when four pieces are produced there is still a large price difference. The biggest advantage of the DMLS additive method is the production time when one part is produced.

The comparison of the last two prototype parts has also shown that the DMLS additive method is advantageous for the production of parts with a complicated geometry. The forming technology was up to five times more expensive especially because of the production of complicated tool kits and of various preparations.

\section{Conclusions}

As follows from the above comparison, it is considerably cheaper to use the DMLS additive method when producing one or more prototype pieces. With 4 pieces, the difference is smaller, but DMLS is still considerably cheaper.

The price of manufactured parts is mainly affected by the right choice of supporting elements, by component orientation and also by appropriate deployment of more parts on the platform. These are the most important factors that can cut down the price, even in the order of thousands of CZK. Forming technology is much more expensive mainly because of the manufacturing of complex tools and various preparations; however, it still plays a unique role in the production of certain prototypes because in the majority of cases 


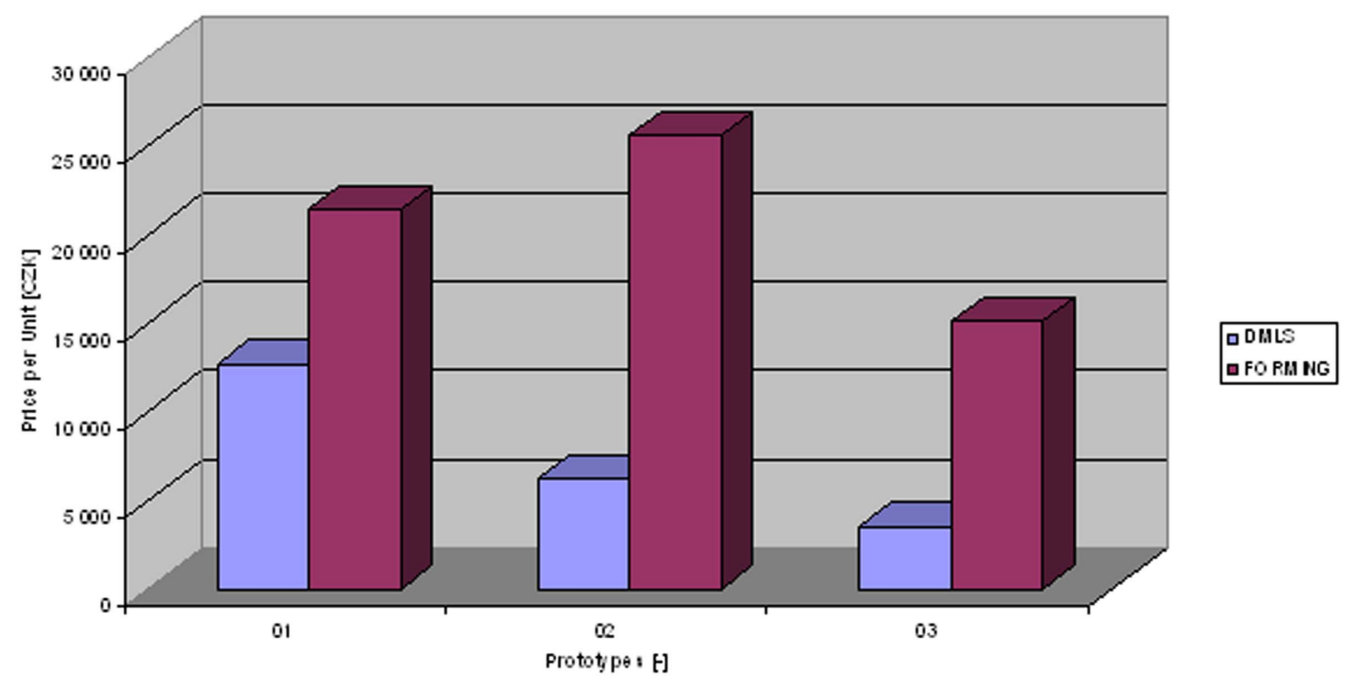

FIGURE 10. Comparison of prototype price per unit in the case of 4 part production.

the same material as that in mass production can be used.

This contribution was intended to provide in-depth information about a progressive method of laser sintering of metal powders, which has many advantages and is suitable for both production of prototypes and of single parts, or for small series production of smaller parts. The major advantage of this method is the time within which the part is manufactured and the unlimited geometric complexity of the parts. This is an indisputable advantage of the DMLS additive method compared to most conventional technologies.

\section{ACKNOWLEDGEMENTS}

This research was supported and co-financed by the "Excellent young scientists" project at Brno University of Technology - registration number CZ.1.07/2.3.00/30.0039, and by MPO CR under the FR-TI4/247 grant, "Research and development of design and technology of energy-efficient spherical roller bearings with brass cage".

\section{REFERENCES}

[1] CHUA, C. K. Rapid Prototyping: Principles and applications. 2nd ed. Hackensack: World Scientific, 2005, 420 s. ISBN 981-238-120-1.

[2] PISKA, M. a kolektiv. Specialni technologie obrabeni. 1. vydani. Brno: CERM, 2009. 246 s. ISBN 978-80-214-4025-8.

[3] NAVRATIL, R. Co znamená Rapid Prototyping http://robo.hyperlink.cz/rapid/index.html [2014-01-19].
[4] SEDLAK, J., RICAN, D., PÍSKA, M. Study of Materials Produced by Powder Metallurgy Using Classical and Modern Additive Laser Technology. Procedia Engineering, 2015, vol. 2015, no. 1, p. 1232-1241. ISSN 1877- 7058.

[5] SEDLAK, J., PTACKOVA, M., NEJEDLY, J., MADAJ, M., DVORACEK, J., ZOUHAR, J., CHARVAT, O., PISKA, M. Material Analysis of Titanium Alloy Produced by Direct Metal Laser Sintering. International Journal of Metalcasting, 2013, vol. 7, no. 2, p. 43-50. ISSN 1939- 5981.

[6] INNOMIA a.s. - firemni stranky http://www . innomia.cz/files/tinymce/files/innomia-cz.pdf [2013-12-22].

[7] Direct Metal Laser Sintering.

http://www.custompartnet.com/wu/ direct-metal-laser-sintering [2014-01-23].

[8] SEDLAK, J. Moderni technologie vyroby implantatu kolenniho kloubniho se specifickymi pozadavky na tvarove a funkcni plochy: Habilitacni prace. Brno: Vysoke uceni technicke v Brne, Fakulta strojniho inzenyrstvi, Ustav strojirenske technologie, 2013. 179 s, 9 priloh.

[9] EOS - Materials for metal. http://ip-saas-eoscms s3.amazonaws. com/public/1af123af9a636e61/ 042696652ecc69142c8518dc772dc113/EOS MaragingSteel_MS1_en.pdf [2014-01-24].

[10] SEKERKA, V. Vyroba dilu technologii DMLS a jejich porovnani s jinymi konvencnimi technologiemi z hlediska ekonomicke narocnosti. Brno: Vysoke uceni technicke v Brne, Fakulta strojniho inzenyrstvi, 2011. $60 \mathrm{~s}$.

[11] Bohdan Bolzano, s.r.o. Czech Republic. Data Sheets. http://www.bolzano.cz/ [2013-04-08]. 